\title{
Stability and diversity of the genetic structure of a Shewanella putrefaciens population in the water column of the central Baltic
}

\author{
Frank Ziemke, Ingrid Brettar, Manfred G. Höfle* \\ GBF - Gesellschaft für Biotechnologische Forschung, AG Mikrobielle Ökologie, Mascheroder Weg 1, \\ D-38124 Braunschweig, Germany
}

\begin{abstract}
The genetic structure of a Shewanella putrefaciens population, the dominant culturable denitrifier in the low oxygen and anoxic water of the central Baltic, was investigated using Randomly Amplified Polymorphic DNA (RAPD) genotyping. Five different procedures were used for the isolation of strains from 2 depth profiles in the Gotland Deep, sampled during 2 consecutive summers (1986 and 1987). The conditions in the water column were comparable for both sampling periods, i.e. the water column was stratified and characterized by pronounced chemical gradients in both years. A total of 59 S. putrefaciens isolates were obtained in 1986 and 54 S. putrefaciens strains in 1987 . Identification of the isolates, to the species level, was carried out using low-molecular-weight (LMW) RNA profiling RAPD fingerprinting, using 3 random decamer primers, enabled the detection of subpopulations within the $S$. putrefaciens population. Thirteen different RAPD genotypes were defined, based upon Neighbor Joining (NJ) and unweighted pair group method using arithmetic averages (UPGMA) clustering The range of RAPD genotypes varied with the isolation procedures, indicating different bacterial clones with different physiological traits within the population, i.e. specific clones were obtained with specific isolation procedures. Thus, the isolation procedure is not merely selective at the species level, but at the clonal level of a given species as well. The striking observation was that all strains isolated in 1987 clustered with RAPD genotypes already found in 1986 . This is interpreted as stability over time of the genetic structure of the $S$. putrefaciens population in the water column of the central Baltic.
\end{abstract}

KEY WORDS: RAPD - Shewanella putrefaciens - Diversity - Baltic Sea Population structure - Bacterial clones $\cdot$ Stability $\cdot$ Denitrifier

\section{INTRODUCTION}

Little is known about the genetic structure of environmental bacteria, particularly about the stability of their populations over time. Recently, 2 studies were conducted on a Burkholderia cepacia population in a lotic ecosystem (Wise et al. 1995, 1996). Other authors have analyzed the population structure of soil bacteria (McArthur et al. 1988, Segovia et al. 1991). However, the best studied bacterial populations are those of medical relevance such as Escherichia coli (Milkman 1973, Selander \& Levin 1980) and Neisseria gonorrhoeae (O'Rourke \& Stevens 1993).

\footnotetext{
-Addressee for correspondence. E-mail: mho@gbf.de
}

Fingerprinting techniques of the chromosomal DNA are modern methods for the determination of bacterial genetic diversity. One of these methods, Randomly Amplified Polymorphic DNA. (RAPD) (Welsh \& McClelland 1990, Williams et al. 1990), utilizes lowstringency PCR (polymerase chain reaction) conditions with short single primers of arbitrary sequence, generating strain-specific banding patterns. The most common application of RAPD in the analysis of bacteria has been the typing of medically relevant species for distinguishing pathogenic from non-pathogenic strains (Rasmussen et al. 1994) or in epidemiological studies (Stephan et al. 1994, Eisen et al. 1995). However, Wang et al. (1993) recommended the use of RAPD fingerprinting for studying bacterial population structure and evolution. 
Shewanella putrefaciens, clustering within the $\gamma$ subclass of the Proteobacteria, was observed to represent the largest fraction of the culturable bacteria and was the most abundant culturable denitrifier obtained from the layers in the Gotland Deep most relevant for denitrification (Brettar \& Rheinheimer 1991, 1992, Brettar \& Höfle 1993). Furthermore, S. putrefaciens may be of importance for the cycling of a large set of elements due to its versatility in using a large array of different electron acceptors. Overviews of the biogeochemical potential of this bacterial species are given by Nealson \& Myers (1992) and Nealson \& Saffarini (1994), Besides the Baltic, as an example of a brackish ecosystem, $S$, putrefaciens inhabits marine ecosystems, e.g. the Black Sea (Nealson et al. 1991), and various freshwater environments (DiChristina \& DeLong 1993). The biogeochemical potential, as well as the occurrence in various aquatic ecosystems, make $S$. putrefaciens an attractive target microorganism for the analysis of the genetic structure of its population in the Baltic Sea.

The central Baltic is the world's largest brackish water environment and can serve as an example for coastal and estuarine environments. The water column of the Gotland Deep was investigated as a station representative for the central Baltic. A major point that makes the Baltic and, particularly, the Gotland Deep an interesting site for the application of new approaches to studying the genetic structure of microbial communities is the large set of long-term records of chemical, hydrographical and microbiological data (Savchuk \& Wulff 1996). Horizontal and vertical exchange processes in the water column are well described (Stigebrandt 1987, Stigebrandt \& Wulff 1987. Wulff et al. 1990, Brettar \& Rheinheimer 1991). This provides a convenient background for putting the genetic structure of a bacterial species into perspective with the chemical conditions for the microflora and the physical transport processes.

In the present study, we used RAPD typing for the analysis of the genetic structure from a set of 113 Shewanella putrefaciens strains isolated from the water column of the Gotland Deep during 2 consecutive summers. Conditions in the water column were stable over these 2 years, thus allowing a comparison of the $S$. putrefaciens population over time.

\section{MATERIAL AND METHODS}

Sampling and field measurements. Seawater samples were taken in the Gotland Deep aboard RV 'Poseidon' from 15 to 17 August 1986 and aboard RV 'Aranda' from 29 to 31 July 1987. The position of Stn BY 15 in the Gotland Deep is $57^{\circ} 20.0^{\prime} \mathrm{N}, 20^{\circ} 3.0^{\prime} \mathrm{E}$, located in the central part of the Baltic Sea. The Gotland Deep at Stn BY 15 has a maximum depth of $240 \mathrm{~m}$, with anoxic water below $140 \mathrm{~m}$ in 1986 and below $130 \mathrm{~m}$ in 1987 . The overall hydrographical and chemical conditions in the water column for the sampling periods in 1986 and 1987 were highly comparable. For detailed descriptions of the station's hydrographical, chemical and microbiological parameters, see Rheinheimer et al. (1989) and Brettar \& Rheinheimer (1991, 1992). Water samples were collected aseptically from the whole water column (10 to $235 \mathrm{~m}$ ) using sterile champagne bottles mounted on modified ZoBell samplers. Samples were processed directly on board, i.e. initial inoculations and incubation steps for the 5 different isolation procedures were carried out immediately after sampling.

Isolation procedures. Five different isolation procedures were used to obtain a broad range of different hetcrotrophic bactcria from the seawater samples: 4 procedures in 1986 (a, b, c, d) and 2 procedures in 1987 (c, e). Details for procedures a-d have been described previously (Höfle \& Brettar 1996; the letters used for the isolation procedures here are directly comparable). Isolation procedure a: a yeast extract-peptone agar medium (ZoBell agar; modified from Oppenheimer \& ZoBell 1952) was inoculated with 0.1 and $0.01 \mathrm{ml}$ of seawater and incubated in the dark at $20^{\circ} \mathrm{C}$ for $2 \mathrm{wk}$. Isolation procedure b: ZoBell agar was inoculated with $0.2 \mathrm{ml}$ of water and incubated anaerobically in a desiccator, in the dark, for $3 \mathrm{wk}$ at $20^{\circ} \mathrm{C}$. Isolation procedure c: a nutrient broth plus nitrate medium $\left(\mathrm{NB}+\mathrm{NO}_{3}\right)$, filled in Hungate tubes, was used, modified from Sreenivasan \& Venkataraman (1956). The inoculum for the Hungate cultures ranged from 10 to $0.001 \mathrm{ml}$ of original seawater sample, applied in 3 replicates in 1986 , and 5 replicates in 1987 . Isolation procedure d: identical to procedure $c$ except that the medium contained only $1 / 10$ of the organic material, i.e. $0.3 \mathrm{~g}$ meat extract $\mathrm{l}^{-1}$ and $0.5 \mathrm{~g}$ Bacto-peptone $\mathrm{l}^{-1}$. Isolation procedure e: a thiosulfate-nitrate medium (TN), adapted from Baalsrud \& Baalsrud (1954), in Hungate tubes was used in the same way as the $\mathrm{NB}+\mathrm{NO}_{3}$ medium. The TN medium was composed of $\mathrm{Na}_{2} \mathrm{SO}_{3} \cdot 5 \mathrm{H}_{2} \mathrm{O}$ $5.0 \mathrm{~g}_{1} \mathrm{KNO}_{3} 2.0 \mathrm{~g}, \mathrm{NH}_{4} \mathrm{Cl} 0.05 \mathrm{~g}, \mathrm{NaCl} 8.0 \mathrm{~g}, 0.01 \mathrm{~g}$ of $\mathrm{FeSO}_{4} \cdot 7 \mathrm{H}_{2} \mathrm{O}$ in $1 \mathrm{~N} \mathrm{HCl}$, deionized water 11 , pH 8.0. For procedures $\mathrm{c}$, d and $\mathrm{e}$, inoculated cultures were incubated for $5 \mathrm{wk}$ in the dark at $20^{\circ} \mathrm{C}$. The characteristics of the different isolation procedures used are illustrated in Table 1.

Bacterial isolates were obtained from these 5 different isolation procedures in the following way: for isolation from solid media (procedures a, b), 50 colonies were picked at random from the plates of each depth and transferred to ZoBell agar plates, using sterile toothpicks. After 2 wk of aerobic incubation, all typi- 
Table 1. Characteristics of the isolation procedures used and total number of strains obtained. MPN: most probable number; NB: nutrient broth

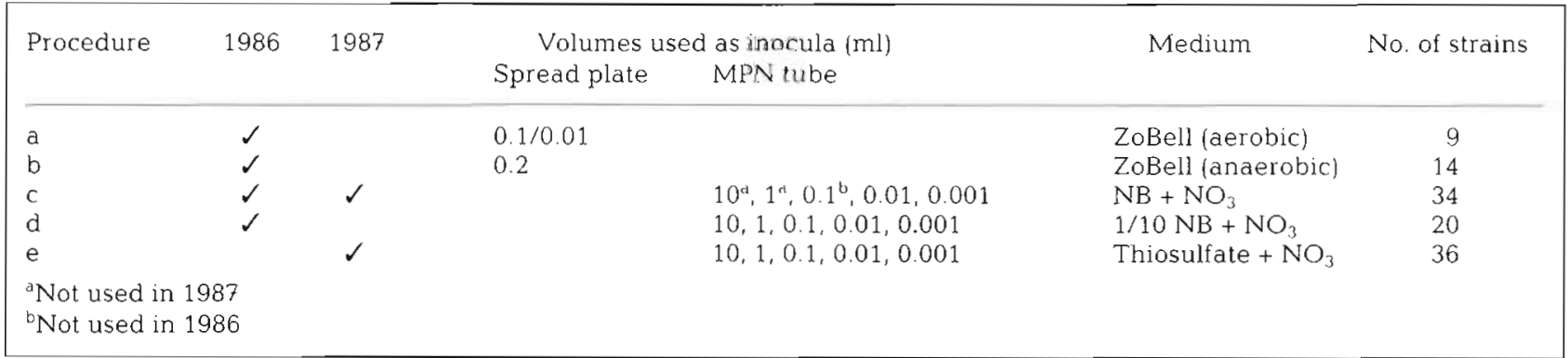

cal colony types were isolated from these master plates. Isolates from the liquid media (procedures $\mathrm{c}, \mathrm{d}$, e) were generated by streaking on ZoBell agar. We used the growth-positive liquid cultures with the lowest and the 2 highest dilutions of the inoculum for isolation in 1986. In 1987, the 3 highest dilution steps were used for procedure $c$, whereas all tubes were used for isolation, i.e. with inocula ranging from 10 to $0.001 \mathrm{ml}$, for procedure e. All different colony types were isolated on ZoBell agar plates and purified by serial transfer to new agar plates, at least 3 times. The purified strains were kept as stock cultures for all further studies at $-70^{\circ} \mathrm{C}$ in a solution of marine broth (Difco Corp.) with reduced salinity (8\%) and 20\% glycerol.

Identification of isolates to the species level. The isolates obtained were identified to the species level by low-molecular-weight (LMW) RNA profiling, as described earlier by Höfle \& Brettar (1996). In 1986, 59 strains, out of 123 isolates, could be assigned to the species Shewanella putrefaciens by this technique and 54 out of 109 in 1987. Data on the LMW RNA profiles and the physiology for the $S$. putrefaciens strains from 1986 have been published elsewhere (Brettar \& Höfle 1993, Höfle \& Brettar 1996).

Randomly Amplified Polymorphic DNA (RAPD) fingerprinting. In a second analytical step, all Shewanella putrefaciens strains were investigated using RAPD analysis (Welsh \& McClelland 1990, Williams et al. 1990) in order to reveal the genetic population structure of the isolates. Bacteria were grown, aerobically, overnight in liquid ZoBell medium at $30^{\circ} \mathrm{C}$. Optical density at $600 \mathrm{~nm}$ was measured and an aliquot containing about $10^{9}$ cells was lysed in alkaline lysis buffer containing $0.05 \mathrm{M}$ $\mathrm{NaOH}$ and $0.25 \%$ SDS. Cellular debris was pelleted and $0.5 \mu \mathrm{l}$ of the supernatant was taken for the PCR reaction. Amplification reactions were carried out in volumes of $25 \mu \mathrm{l}$ containing $20 \mathrm{mM}$ Tris-Cl $\mathrm{pH} 8.3,2 \mathrm{mM} \mathrm{MgCl}, 25 \mathrm{mM} \mathrm{KCl}, 0.05 \%$ Tween $20,0.1 \mathrm{mg} \mathrm{ml}^{-1}$ gelatine, $200 \mu \mathrm{M}$ each of dATP, dCTP, dGTP and dTTP (Pharmacia), $2 \mu \mathrm{M}$ primer and $0.5 \mathrm{U}$ AmpliTaq DNA Polymerase (Perkin-Elmer Cetus). A Perkin-Elmer GeneAmp 9600 thermal cycler was used for amplification, programmed for 45 cycles of denaturation at $94^{\circ} \mathrm{C}$ for $15 \mathrm{~s}$, annealing at $36^{\circ} \mathrm{C}$ for $60 \mathrm{~s}$ and elongation at $72^{\circ} \mathrm{C}$ for $120 \mathrm{~s}$, followed by a final amplification step at $72^{\circ} \mathrm{C}$ for $10 \mathrm{~min} .8 \mu \mathrm{l}$ of the amplification products were separated by electrophoresis in a $1.5 \%$ agarose gel (FMC Seakem) and visualized by ethidium bromide staining.

Seventeen decamer RAPD primers were screened for their ability to discriminate Shewanella putrefaciens reference strains. Three primers giving informative banding patterns in agarose electrophoresis gels were chosen for the analysis of the environmental isolates (Table 2).

Reproducibility of the RAPD patterns was demonstrated by typing Shewanella putrefaciens reference strains in triplicate independent experiments (data not shown). Identical banding patterns showed a reproducibility at a level of $96.7 \%$ similarity within a gel and 95.0\% similarity between different gels, using Pearson's correlation and UPGMA clustering algorithm (see below).

Data processing and statistical analysis. Gel images were digitized as TIFF files using an EASY camera (Herolab GmbH, Wiesloch, Germany). The TIFF files were imported into the software package Gelcompar (Applied Maths, Kortrijk, Belgium). Gels were normalized referring to a $1 \mathrm{~kb}$ ladder (Gibco) serving as a database standard. We used the whole informative part of each lane for analysis, i.e. all bands within the range from 0.2 to $6.0 \mathrm{~kb}$ were analyzed. The RAPD pat-

Table 2. Characteristics of the RAPD primers used

\begin{tabular}{|lcccc|}
\hline \multirow{2}{*}{ Primer } & Sequence & GC content (\%) & \multicolumn{2}{c|}{ No. of bands produced } \\
& & & Range & Mean \\
\hline A & 5'CTGGCGGCTG3' & 80 & $3-11$ & 7.0 \\
B & 5'ATCTGGCAGC3' & 60 & $2-14$ & 6.7 \\
C & 5'GGTCAGTAGC3' & 60 & $2-11$ & 5.6 \\
\hline
\end{tabular}



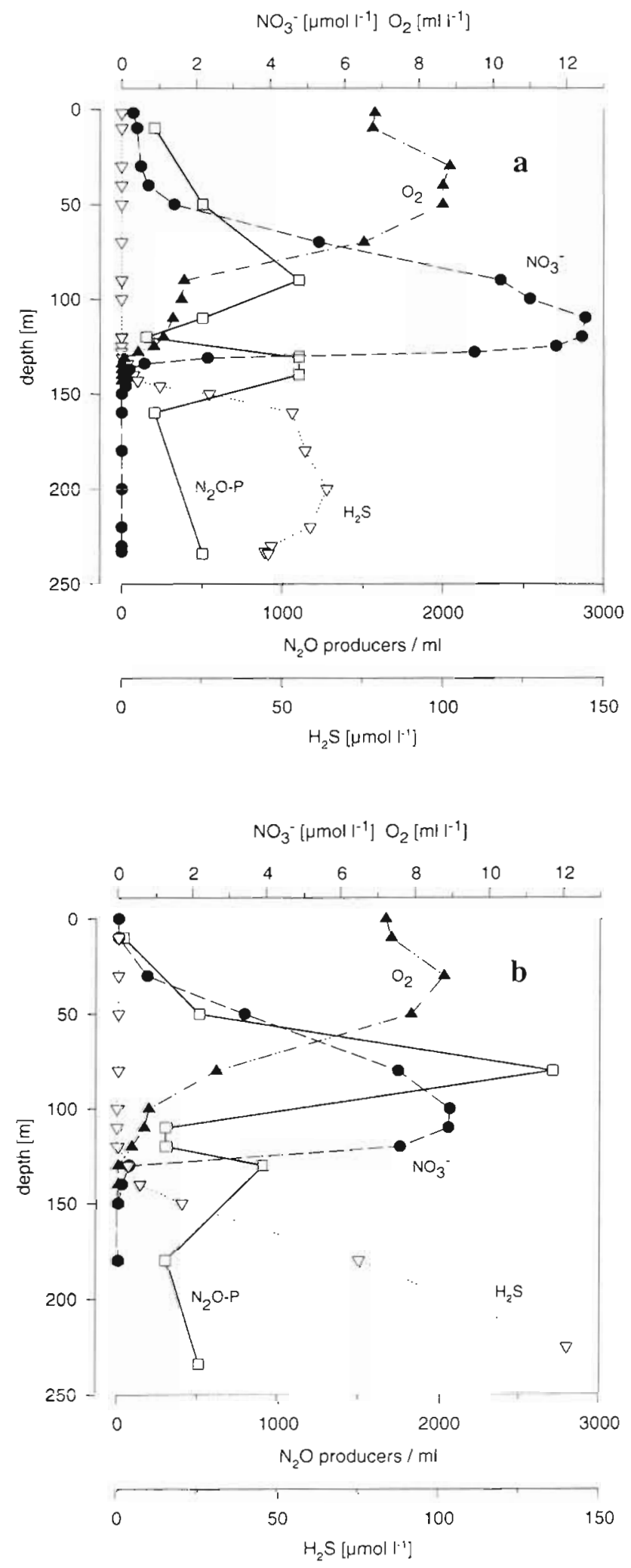

Fig. 1 Depth profiles of chemical parameters and depth distribution of $\mathrm{N}_{2} \mathrm{O}$-producing bacteria $\left(\mathrm{N}_{2} \mathrm{O}-\mathrm{P}\right)$ in the water column of the Gotland Deep (Baltic Sea) in the summers of (a) 1986 and (b) 1987 terns from 3 gels were combined for each strain (each gel analyzing samples generated using a different primer), creating a synthetic gel in this way. Combined banding patterns were compared using Pearson's product moment correlation and clustered using the Neighbor Joining (NJ) algorithm (Saitou \& Nei 1987) and the unweighted pair group method using arithmetic averages (UPGMA) (Sokal \& Michener 1958). Clusters of similar strains are hereafter termed RAPD genotypes.

\section{RESULTS}

\section{Chemical and microbiological characterization of the sampling site}

Background information about chemical and microbiological parameters in the water column of the Gotland Deep are given in Fig. 1. Both depth profiles were typical for summer situations during periods of stagnation (Rheinheimer et al. 1989, Brettar \& Rheinheimer $1991,1992)$. Based on the chemical data, the water column could be separated into 3 characteristic zones: (1) the oxic zone, with oxygen concentrations close to the saturation level and low nitrate concentrations, from the surface down to the halocline; (2) the suboxic zone, with low oxygen concentrations but high nitrate concentrations, beneath the halocline in 60 to $90 \mathrm{~m}$ depths down to the oxic-anoxic interface at approximately 130 to $140 \mathrm{~m}$ depths; and (3) the anoxic zone, characterized by the presence of $\mathrm{H}_{2} \mathrm{~S}$. The observed stratification was typical for the water column in the Gotland Deep for both years.

The number of $\mathrm{N}_{2} \mathrm{O}$-producing bacteria in the samples taken in 1986 and 1987 was estimated using the MPN method and $\mathrm{NB}+\mathrm{NO}_{3}$ medium (Fig. 1). The number of $\mathrm{N}_{2} \mathrm{O}$-producing bacteria were low in the oxic and anoxic zones. Two maxima were observed in the suboxic zone, one at the bottom of the halocline and the second at the oxic-anoxic interface. The peak of $\mathrm{N}_{2} \mathrm{O}$-producing bacteria, at the halocline, in 1987 was far more pronounced than in 1986. But in general, profiles of both years were similar due to the stagnant situation in the deep water below the halocline.

\section{Genotypic grouping of strains}

The genetic structure of Shewanella putrefaciens isolates from depth profiles of 2 consecutive years from the central Baltic was analyzed using RAPD fingerprints. Three decamer random primers were used to generate a combined banding pattern in agarose electrophoresis gels for each of the 113 strains. Examples of 

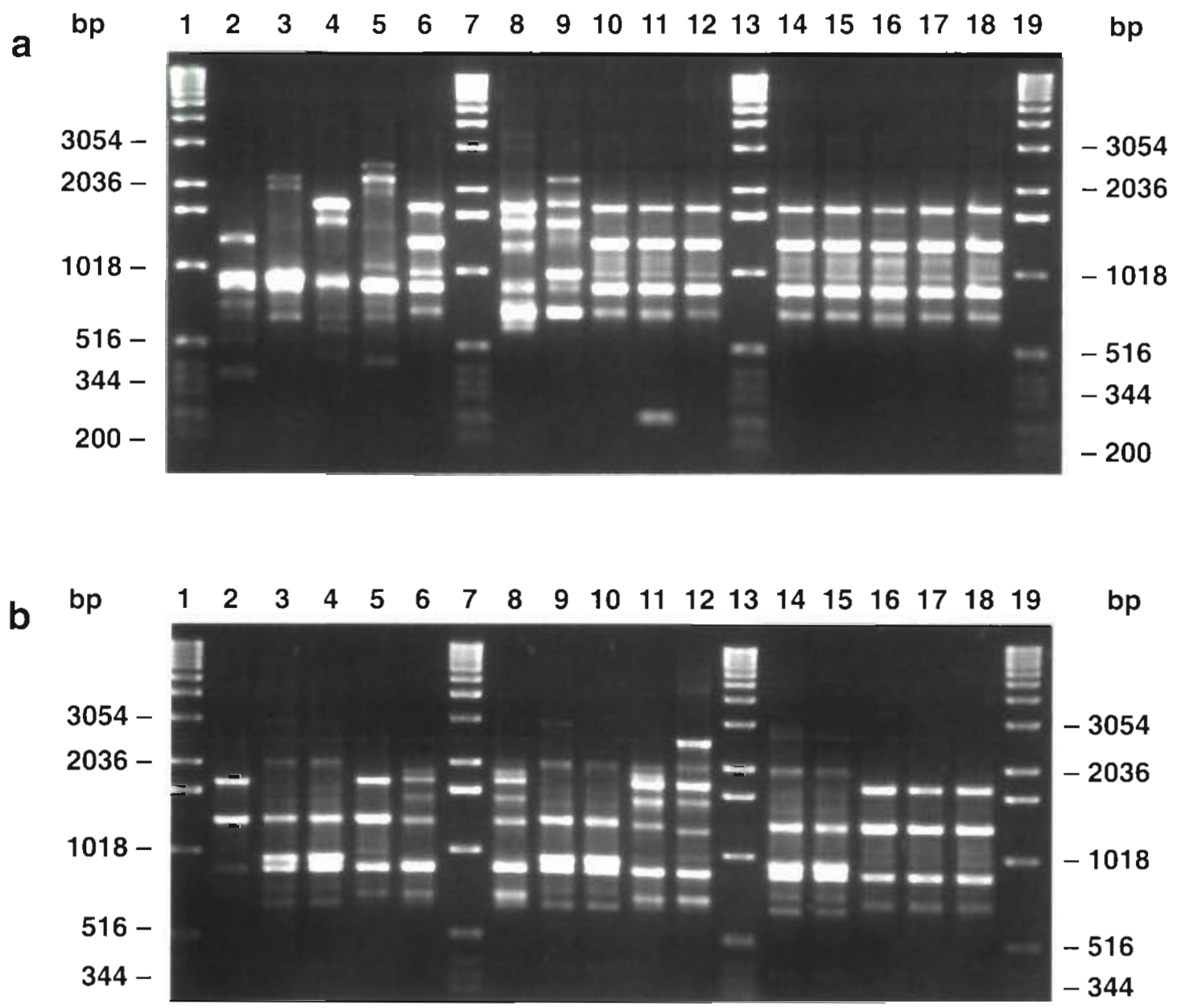

Fig. 2. RAPD patterns of Shewanella putrefaciens isolates from the Gotland Deep generated with primer A. Isolates were obtained from different isolation procedures from different depths. (a) Lanes: 1, 7, 13, $191 \mathrm{~kb}$ ladder (Gibco), lane 2 OS110 (F120-c: RAPD genotype F, $120 \mathrm{~m}$ depth, isolation procedure c), lane 3 OS205 (E-110-c), lane 4 OS122 (C-235-c), lane 5 OS208 (D110-d), lane 6 OS195 (A-140-b), lane 8 OS275 (I-160-d), lane 9 OS183 (H-120-b), lane 10 OS601, lane 11 OS604 (both A-10-e), lane 12 OS612 (A-50-e), lanes 14 to 18 OS 613, OS 615, OS616, OS617, OS620 (all A-50-e). (b) Lanes: 1, 7, 13, $191 \mathrm{~kb}$ ladder (Gibco), lane 2 OS687 (A-10: RAPD genotype A, $10 \mathrm{~m}$ depth), lane 3 OS688, lane 4 OS690 (both F-80), lane 5 OS694 (A-80), lane 6 OS695, lane 8 OS696 (both B-120), lane 9 OS697, lane 10 OS698 (both F-120), lane 11 OS699, lane 12 OS700 (both B-120), lane 14 OS703, lane 15 OS704 (both F-180), lanes 16 to 18 OS 709, OS 710, OS711 (all A-110); all isolates were obtained from isolation procedure $\mathrm{C}$

RAPD fingerprints are given in Fig. 2. Fingerprint patterns of different RAPD genotypes, isolated from different depths in 1986, and the most frequent RAPD genotype A isolated from 2 depths in 1987, generated with primer A, are shown in Fig. 2a. Note the similar patterns of RAPD genotype A from 1986 (lane 6) and from 1987 (lanes 10 to 12,14 to 18 ). The banding patterns of the frequent RAPD genotypes $\mathrm{A}, \mathrm{B}$ and $\mathrm{F}_{\text {, iso- }}$ lated from different depths in 1987, are shown in Fig. 2b.

Normalized RAPD patterns were compared using Pearson's product moment correlation. The resulting similarity matrices were clustered using 2 different algorithms: (1) Neighbor Joining ( $\mathrm{NJ}_{\text {; }}$ Saitou \& Nei
1987) and (2) UPGMA (Sokal \& Michener 1958). In contrast to UPGMA that determines the correlation between 2 linked patterns, NJ indicates the calculated distance between 2 patterns. Grouping of the strains was consistent with both algorithms. A comprehensive dissimilarity tree for all strains from 1986 and 1987. derived by NJ clustering, is shown in Fig. 3. The sum of all branches in the horizontal direction, which one follows in order to link 2 strains, is a measure of the distance between the strains. Thirteen RAPD genotypes were defined within the NJ tree, which was confirmed by grouping the strains with the UPGMA algorithm choosing a threshold level of $70 \%$ similarity for all strains (data not shown). 


\section{Frequency of RAPD genotypes}

The frequency of all 13 RAPD genotypes and the number of strains per genotype for each year are summarized in Table 3. Frequency is defined as the percentage of a given RAPD genotype, in relation to the total number of isolated Shewanella putrefaciens strains, in order to distinguish this term from the abundance of a RAPD genotype in situ, i.e. in the ecosystem. Six frequent RAPD genotypes (frequency of at least $5 \%$ ) were isolated in 1986. Eighty-three percent of all strains belonged to these frequent RAPD genotypes A, B, C: F, G and $\mathrm{K}$. The remaining $17 \%$ were distributed among RAPD genotypes D, E, H, I, L, M and $N$, and each was represented by 1 or 2 strains only. The striking observation was that 5 of the 6 frequent RAPD genotypes from 1986 were still frequent in 1987, although different isolation procedures were used.

The frequent RAPD genotypes $A, B$, C, $\mathrm{F}$ and $\mathrm{K}$ comprised $98 \%$ of the total number of strains in 1987. The proportion of RAPD genotype A, which was also isolated in high frequency in 1986 $(30 \%)$, almost doubled in 1987 (59\%). This may reflect the use of a different medium employed for isolation (see below). RAPD genotype $G$ was the only frequent RAPD genotype which was not recovered in 1987. All other RAPD genotypes, which were missing in 1987 (D, E, I, L, M and N comprising $15 \%$ of the total number of strains in 1986), were less frequent.

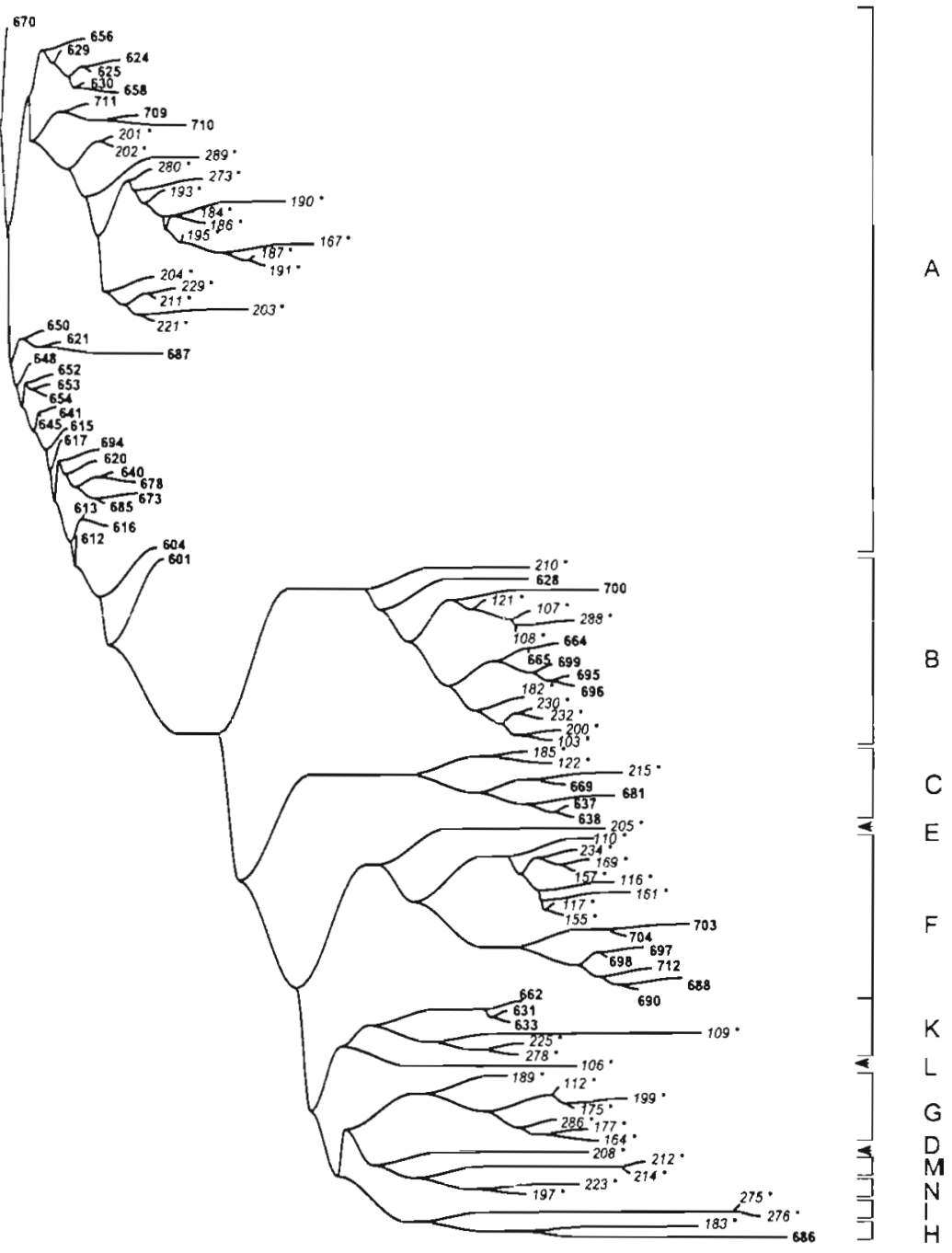

Fig. 3. Comprehensive dissimilarity tree for Shewanella putrefaciens strains from 2 depth profiles in the central Baltic based on RAPD fingerprinting with 3 random primers. Normalized RAPD patterns were compared using Pearson's product moment correlation and clustered with Neighbor Joining algorithm. The sum of all branches in the horizontal direction linking 2 strains is a measure of the distance between strains. "Strains isolated in 1986. The resulting RAPD genotypes are indicated with brackets or arrows

\section{Influence of the isolation procedure on the RAPD genotypes obtained}

Four different isolation procedures were used in 1986, yielding 13 RAPD genotypes, whereas in 1987. 6 different RAPD genotypes were obtained by 2 isolation procedures. The isolation procedure had a strong influence on the selection of the RAPD genotypes, as shown in Table 4 . Three characteristics of the isolation procedure were determined to cause variation in the range of RAPD genotypes obtained: (1) the composition of the medium itself, (2) the concentration of organic nutrients and (3) the incubation conditions
Different RAPD genotypes were recovered with 2 completely different media in 1987: $\mathrm{NB}+\mathrm{NO}_{3}$ and $\mathrm{TN}$ medium, the latter with only small amounts of carbon source available. The RAPD genotypes $A$ and $B$ were common tor both media, whereas RAPD genotype $F$, represented by 7 isolates on $\mathrm{NB}+\mathrm{NO}_{3}$ medium, was not obtained using TN medium. The latter medium, on the other hand, enabled growth of the RAPD genotypes $C$ and $K$, which were not isolated using NB + $\mathrm{NO}_{3}$ medium.

The use of the same medium with different nutrient concentrations resulted in the isolation of different RAPD genotypes for 1986. $\mathrm{NB}+\mathrm{NO}_{3}$ medium enabled growth of RAPD genotype F only, when smaller amounts of 
inoculum were used, while 5 additional RAPD genotypes $(B, C, G, I$ and $N$ ) were obtained using the same medium, but diluted 10 -fold.

The availability of oxygen during incubation of ZoBell agar plates demonstrated a selective impact on the RAPD genotypes recovered. Aerobic incubation selected in favor of RAPD genotype $F$, which was not obtained using anaerobically incubated ZoBell agar plates. RAPD genotype $A$, on the other hand, which was only isolated once from aerobically incubated plates, dominated under anaerobic conditions.

Significant differences in the use of media were observed for the RAPD genotypes $A$ and $F$, which therefore should be described in more detail: RAPD genotype A was most frequently selected using TN medium and ZoBell agar plates incubated anaerobically. RAPD genotype A was, furthermore, present in all media when a large volume of inoculum $(10 \mathrm{ml})$ was added. In liquid media with small volumes of inoculum $(0.01,0.001 \mathrm{ml})$, RAPD genotype A was absent, except when TN medium was used. RAPD genotype $F$, on the other hand, was isolated mainly using $\mathrm{NB}+\mathrm{NO}_{3}$ medium, exclusively using small amounts of inoculum
Table 3. Frequency of RAPD genotypes obtained in 1986 and 1987, in comparison to the total number of Shewanella putrefaciens strains isolated per year and depth profile, resulting from the RAPD analysis using 3 decamer primers. Common RAPD genotypes for both years are given in the upper part of the table. Lower part represents RAPD genotypes detected ony in 1986

\begin{tabular}{|lrrrr|}
\hline RAPD & \multicolumn{2}{c}{1986} & \multicolumn{2}{c|}{1987} \\
genotype & $\begin{array}{c}\text { Frequency } \\
(\%)\end{array}$ & $\begin{array}{c}\text { No. of } \\
\text { strains }\end{array}$ & $\begin{array}{c}\text { Frequency } \\
(\%)\end{array}$ & $\begin{array}{c}\text { No. of } \\
\text { strains }\end{array}$ \\
\hline A & 30 & 18 & 59 & 32 \\
B & 17 & 10 & 13 & 7 \\
C & 5 & 3 & 7 & 4 \\
F & 14 & 8 & 13 & 7 \\
H & 2 & 1 & 2 & 1 \\
K & 5 & 3 & 6 & 3 \\
Sum & 73 & 43 & 100 & 54 \\
D & 2 & 1 & - & - \\
E & 2 & 1 & - & - \\
G & 12 & 7 & - & - \\
I & 3 & 2 & - & - \\
L & 2 & 1 & - & - \\
M & 3 & 2 & - & - \\
N & 3 & 2 & - & - \\
Sum & 27 & 16 & - & - \\
\hline
\end{tabular}

Table 4. Occurrence of the different RAPD genotypes obtained by isolation procedures a-e. Each character represents a single isolate with the indicated RAPD genotype. Dilution steps indicated in bold are assumed important in terms of abundance in the ecosystem. a: modified ZoBell agar aerobically incubated; b: modified ZoBell agar anaerobically incubated; $\mathrm{c}: \mathrm{NB}_{+}+\mathrm{NO} \mathrm{O}_{3}$ medium; d: $1 / 10$ nutrient broth $(\mathrm{NB})+\mathrm{NO}_{3}$ medium; e: thiosulfate-nitrate (TN) medium; o: no Shewanella putrefaciens isolates obtained

\begin{tabular}{|c|c|c|c|c|c|c|c|c|c|c|c|c|c|}
\hline \multirow{3}{*}{$\begin{array}{l}\text { Year of } \\
\text { sampling }\end{array}$} & \multirow{3}{*}{ Depth $(\mathrm{m})$} & \multicolumn{10}{|c|}{ Isolates from liquid media (dilution series) } & \multicolumn{2}{|c|}{ Isolates from agar plates } \\
\hline & & \multicolumn{5}{|c|}{$\begin{array}{l}\text { Procedure c } \\
\text { Inoculum (ml) }\end{array}$} & \multicolumn{5}{|c|}{$\begin{array}{l}\text { Procedure d } \\
\text { Inoculum (ml) }\end{array}$} & \multirow{2}{*}{$\begin{array}{l}\text { Procedure a } \\
\text { Inoculum } \\
0.1 \mathrm{ml} \text { plate }\end{array}$} & \multirow{2}{*}{$\begin{array}{l}\text { Procedure } \\
\text { Inoculum } \\
0.2 \mathrm{ml} \text { plate }\end{array}$} \\
\hline & & 10 & 1 & 0.1 & 0.01 & 0.001 & 10 & 1 & 0.1 & 0.01 & 0.001 & & \\
\hline \multirow[t]{13}{*}{1986} & 10 & 0 & 0 & & o & o & & & & & & o & \\
\hline & 30 & & & & & & & & & & & 0 & \\
\hline & 50 & B & 0 & & 0 & 0 & & & & & & 0 & \\
\hline & 90 & L & 0 & & 0 & 0 & & & & & & $\mathrm{~F}$ & \\
\hline & 110 & $A A A A E$ & 0 & & o & 0 & $A A B D K$ & $M M$ & o & C I & 0 & & \\
\hline & 120 & B & B K & & F & 0 & o & 0 & $\mathrm{~A}$ & $\mathbf{N}$ & o & F F & $\mathrm{AAACH}$ \\
\hline & 130 & $G$ & 0 & & $\mathrm{~F}$ & $\mathrm{~F}$ & $\mathrm{BK}$ & A & $\mathrm{A}$ & B B & 0 & $G$ & $A A G$ \\
\hline & 140 & & & & & & 0 & o & o & G & 0 & A & $\mathrm{AA}$ \\
\hline & 160 & $o$ & 0 & & o & 0 & 0 & 0 & 0 & F I & 0 & & \\
\hline & 180 & & & & & & & & & & & $\mathrm{~F}$ & $N$ \\
\hline & 235 & B C & o & & o & 0 & & & & & & $B G G$ & $\mathrm{ABG}$ \\
\hline & & \multicolumn{5}{|c|}{$\begin{array}{l}\text { Procedure } \mathrm{c} \\
\text { Inoculum (ml) }\end{array}$} & \multicolumn{5}{|c|}{$\begin{array}{l}\text { Procedure e } \\
\text { Inoculum (ml) }\end{array}$} & & \\
\hline & & 10 & 1 & 0.1 & 0.01 & 0.001 & 10 & 1 & 0.1 & 0.01 & 0.001 & & \\
\hline \multirow[t]{8}{*}{1987} & 10 & & & A & $\mathrm{AH}$ & 0 & A & A & o & 0 & 0 & & \\
\hline & 50 & & & 0 & 0 & o & A A & o & $\mathrm{A} A \mathrm{~A}$ & A A & 0 & & \\
\hline & 80 & & & 0 & 0 & A F F & A A & B & $\mathrm{AA}$ & K K & 0 & & \\
\hline & 110 & & & $A A A$ & 0 & $\mathrm{~F}$ & $\mathrm{~A}$ & $A$ & $\mathrm{C}$ & 0 & 0 & & \\
\hline & 120 & & & o & B B F F & B B & o & $\mathrm{CC}$ & $\mathrm{AA}$ & 0 & 0 & & \\
\hline & 130 & & & o & 0 & 0 & A & $\mathrm{A}$ & A & A & 0 & & \\
\hline & 180 & & & 0 & F F & 0 & $\mathrm{~A} A$ & $\mathrm{~A}$ & A & 0 & o & & \\
\hline & 235 & & & o & 0 & 0 & $\mathrm{~K}$ & $B B$ & $C$ & A & 0 & & \\
\hline
\end{tabular}


$(0.01$ and $0.001 \mathrm{ml})$, and ZoBell agar medium incubated aerobically.

\section{Abundance of RAPD genotypes in the water column of the Gotland Deep}

The spatial distribution of Shewanella putrefaciens in the water column of the Gotland Deep can be derived from the number of $\mathrm{N}_{2} \mathrm{O}$-producing bacteria (Fig. 1). As all $S$. putrefaciens strains isolated in both years were able to produce $\mathrm{N}_{2} \mathrm{O}$ (Brettar \& Höfle 1993) and, furthermore, all $\mathrm{N}_{2} \mathrm{O}$-producing isolates from the 1987 sampling were identified as $S$. putrefaciens (data not shown), the number of $\mathrm{N}_{2} \mathrm{O}$-producing bacteria calculated using the most probable number (MPN) method may be used as a rough estimate for the number of culturable $S$. putrefaciens cells in the water column.

In 1986, the majority of the strains obtained were isolated from the suboxic zone of the water column, which is in agreement with the data regarding the $\mathrm{N}_{2} \mathrm{O}$-producing isolates. However, in 1987, more strains compared to the number of isolates obtained in 1986 were isolated from the oxic zone, but most of the strains were obtained from the suboxic zone as well.

In order to have a realistic estimate which RAPD genotypes of Shewanella putrefaciens were abundant in the water column, the data derived using $\mathrm{NB}+\mathrm{NO}_{3}$ media must be considered in particular. As the $S$. putrefaciens strains isolated using these media were obtained from 10-fold dilution steps of an MPN procedure, reducing the amount of inoculum of the original water sample 10 times with each step, it can be assumed that RAPD genotypes obtained from the high dilution steps, and therefore small amounts of inoculum $(0.001$ and $0.01 \mathrm{ml})$, were abundant in situ. The depth distribution of the RAPD genotypes along the water column will be considered separately for each medium, because of the strong influence of the isolation procedure.

$\mathrm{NB}+\mathrm{NO}_{3}$ medium was used in both years (see Table 4). In 1986, RAPD genotype F was obtained exclusively in the highest dilution steps of samples from the suboxic zone $(120,130 \mathrm{~m})$. Other RAPD genotypes were present, but were isolated only from dilution steps using 1 or $10 \mathrm{ml}$ inocula. In 1987, the RAPD genotype $F$ was detected in samples of decreasing depths to the bottom of the halocline $(80 \mathrm{~m})$ and in samples of increasing depths to $180 \mathrm{~m}$. Additionally, the RAPD genotypes A and B occurred in the denitrification layer $(120 \mathrm{~m})$, indicating a higher abundance of these genotypes in 1987

In 1986 , the $1 / 10$ diluted $\mathrm{NB}+\mathrm{NO}_{3}$ medium was used for comparison with undiluted $\mathrm{NB}+\mathrm{NO}_{3}$ medium. The diluted medium generated the highest number of different RAPD genotypes in MPN tubes with a low inoculum (6 RAPD genotypes within 8 isolates, including genotypes $B$ and $F$, each from $0.01 \mathrm{ml}$ inoculum).

A pronounced dominance of RAPD genotype A was observed employing TN medium (used only in 1987) including the isolates obtained from samples of the denitrification layer. Additionally, the RAPD genotypes $\mathrm{K}(80 \mathrm{~m})$ and $\mathrm{C}(110 \mathrm{~m})$ were abundant in the suboxic zone. Each genotype was obtained using the highest dilution step of samples from the corresponding depth. RAPD genotype $F$ was not isolated with this medium.

ZoBell agar plates, incubated aerobically, allowed the isolation of Shewanella putrefaciens from 1986 samples of $90 \mathrm{~m}$ and deeper, with a dominance of RAPD genotypes F and G. Mainly, RAPD genotype A was obtained from anaerobically incubated ZoBell agar plates, irrespective of the depth.

In summary, this study demonstrated that the isolation procedures employed had a strong influence on the structure of the Shewanella putrefaciens population isolated from the water column of the Gotland Deep, as different media selected in favor of different RAPD genotypes. It could be further demonstrated that the RAPD genotypes most frequently isolated were present in the water column for at least $1 \mathrm{yr}$.

\section{DISCUSSION}

\section{Intraspecies diversity of Shewanella putrefaciens}

Shewanella putrefaciens exhibited intraspecies diversity, as can be concluded from the data shown in Fig. 3. It is important to mention that the given tree is not phylogenetic, but a phenetic dissimilarity tree based on the comparison of genotypic traits of the isolated strains. RAPD patterns from 3 different primers were compared, taking into account not only the presence or absence of bands, but the relative intensities of the bands as well. Pearson's product moment correlation was used to create a similarity matrix from the RAPD patterns. This algorithm enables a comparison of the overall similarity of patterns as an alternative to band matching, and avoids subjective evaluations of the presence and absence of faint bands. Two mathematicaily different algorithms were used to generate dendrograms from the similarity matrix. Clustering the strains using the NJ algorithm resulted in 13 distinct groups, which were referred to as RAPD genotypes. The similarity matrix can also be represented by a tree based on the UPGMA algorithm. UPGMA arranges the strains into the same RAPD genotypes as those derived by NJ clustering, using a threshold level of $70 \%$ similarity. This indicates a statistical consistency of the grouping. 
RAPD fingerprinting provides a useful tool for analysis of the genetic structure of closely related bacteria. Since RAPDs fingerprint the whole genome this method is far more sensitive in terms of detecting genetic diversity than, for example, 16S rDNA sequencing (van Rossum et al. 1995). Comparison of RAPD data with results from Restriction Fragment Length Polymorphism (RFLP) analysis indicates higher sensitivity of RAPD fingerprinting (Welsh et al. 1992). For many bacteria, RFLP groups can be subgrouped using RAPDs, e.g. Brucella (Fekete et al. 1992) and Borrelia (Welsh et al. 1992). Wang et al. (1993) used 5 primers to calibrate the RAPD data with the Multilocus Enzyme Electrophoresis (MLEE) method which is most widely used in studies of population genetics. Three or more subgroups were distinguished for each MLEE group of strains from the Escherichia coli ECOR collection with each of the RAPD primers used. In general, results from RAPD fingerprinting are in agreement with data obtained from MLEE, DNA. DNA hybridization and rDNA RFLP analysis (Baranton et al. 1992, Welsh et al. 1992, Wang et al. 1993).

Comparison of the genetic diversity observed in the Shewanella putrefaciens populations with data from other bacteria is difficult, because there are few data available for single sampling sites. Data from studies of medically relevant bacteria and from environmental bacteria are shown in Table 5 . A rough estimate of diversity may be derived from the ratio of genotypes to the total number of isolated strains. Wise et al. (1996) isolated Burkholderia cepacia strains from a single sampling site of a river sediment and analyzed the population using MLEE. These data suggest that $B$. cepacia exhibits greater variability among different sites than within a given site over time (Wise et al. 1995, 1996). Paffetti et al. (1996) analyzed the genetic structure of a Rhizobium meliloti population consisting of 96 isolates from 2 Italian soils using RAPD fingerprinting. They reported considerable variation within the population, as each strain was a distinct genetic unit. In this context the observed diversity of the $S$. putrefaciens population obtained from the Gotland Deep seems to be at a lower level.

\section{Selectivity of different isolation procedures}

A pronounced selection for certain RAPD genotypes, according to the respective isolation procedure, is indicated by the set of RAPD genotypes obtained, dependent upon the media and the size of the inoculum (Table 4). Three factors, mainly, regulate the recovery of a specific genotype from dilution series: (1) the abundance of the genotype in the natural sample, (2) the growth or survival of the genotype in the respective medium and (3) the competitiveness of the genotype in the presence of other bacteria. For the recovery of RAPD genotypes out of dilution series this means that in MPN tubes with a large inoculum, the resulting RAPD genotypes were able to outcompete others in the respective medium, and in MPN tubes with the smallest inoculum, in cases where isolates were obtained, the resulting RAPD genotype can be considered to have a high abundance in situ.

Using procedure c, RAPD genotype F was obtained exclusively when small inocula were used, indicating high abundances of RAPD genotype $F$ in both years. But RAPD genotype $F$ was not able to compete well in the presence of other bacteria. In contrast, RAPD genotype B demonstrated a high abundance in samples from 1987, but also was detected in MPN tubes with large inocula in 1986. RAPD genotype B seems to be more competitive than RAPD genotype $F$ in the presence of other bacteria. As $\mathrm{NB}+\mathrm{NO}_{3}$ medium enabled the growth of a large set of strains (see Brettar \& Höfle 1993), the appearance of specific RAPD genotypes may be regarded either as an indication of their abundance (with small inoculum) or as a result of the competitive selection among the bacteria present

Table 5. Studies concerning the diversity of bacterial populations. For comparison of the different methods the diversity is roughly estimated by the ratio of the number of genotypes compared to the total number of strains

\begin{tabular}{|c|c|c|c|c|c|c|}
\hline Organism & Sampling site & Method & $\begin{array}{l}\text { No. of } \\
\text { isolates }\end{array}$ & $\begin{array}{l}\text { No. of } \\
\text { genotypes }\end{array}$ & $\begin{array}{l}\text { Genotype to } \\
\text { isolate ratio }\end{array}$ & Source \\
\hline Burkholderia cepacia & $\begin{array}{l}\text { River sediment, } \\
\text { stream continuum }\end{array}$ & MLEE & 213 & 164 & 0.77 & Wise et al. (1995) \\
\hline Burkholderia cepacia & $\begin{array}{l}\text { River sediment, } \\
\text { time series at a single site }\end{array}$ & MLEE & 217 & 65 & 0.30 & Wise et al. (1996) \\
\hline Rhizobium meliloti & 2 soils & RAPD & 96 & 96 & 1.0 & Paffetti et al. (1996) \\
\hline Escherichia coli & Various hosts & MLEE & 72 & 62 & 0.86 & Selander et al. (1987) \\
\hline Escherichia coli & Single hosts & MLEE & 550 & 53 & 0.10 & Selander et al. (1987) \\
\hline Shewanella putrefaciens & Gotland Deep 1986 & RAPD & 59 & 13 & 0.22 & This study \\
\hline Shewanella putrefaciens & Gotland Deep 1987 & RAPD & 54 & 6 & 0.11 & This study \\
\hline
\end{tabular}


Using procedure $d\left(1 / 10 \mathrm{NB}+\mathrm{NO}_{3}\right)$ a relatively heterogeneous selection of RAPD genotypes was obtained from samples taken from 110 to $160 \mathrm{~m}$. Although the same samples were used for inoculation, the RAPD genotypes obtained were different from those obtained by procedure $\mathrm{c}\left(\mathrm{NB}+\mathrm{NO}_{3}\right)$. As both media differ only in the concentration of nutrient broth, we consider the availability of organic carbon as the factor selecting in favor of RAPD genotype $F$ and against the genotypes obtained using $1 / 10 \mathrm{NB}+\mathrm{NO}_{3}$.

Procedure e (TN medium) selected in favor of RAPD

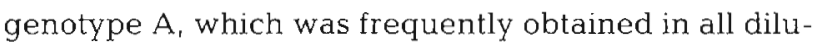
tion series. Since TN medium contains only organic matter from aged seawater as carbon source, we assume that isolation using this medium reflects mainly these RAPD genotypes able to survive in this medium for the incubation period of $5 \mathrm{wk}$. This is likely because visible growth was not observed in $\mathrm{TN}$ medium, nor is there any indication from the literature that Shcwanella putrefaciens is able to grow under these conditions (Nealson \& Myers 1992).

Isolation of characteristic colony types on ZoBell agar resulted in a set of RAPD genotypes most similar to the set obtained using procedure $\mathrm{C}$, when incubated aerobically, i.e. RAPD genotype $F$ was dominating. On the other hand, RAPD genotype A was the dominant genotype for plates incubated anaerobically. Thus, different amounts of oxygen available as electron acceptors for the same water samples resulted in a completely different set of RAPD genotypes, despite the fact that all RAPD genotypes were able to grow aerobically.

In the following, the characteristics of the frequent and abundant RAPD genotypes are summarized. RAPD genotype A was obtained using all isolation procedures, particularly using MPN tubes with large inocula. We assume that RAPD genotype $A$ was less abundant than RAPD genotypes $B$ and $F$, but was rather competitive in all media used. Low concentrations of carbon (TN medium) and low oxygen tensions (isolation procedure b) appear to support RAPD genotype A over other genotypes. RAPD genotype B was obtained with all isolation procedures and from all dilution steps. In 1987 , RAPD genotype $B$ had the same high abundance as RAPD genotype F. RAPD genotype $B$ is considered, therefore, to be a versatile, abundant and competitive genotype. RAPD genotype F was restricted, in 1986 and 1987, to MPN cultures generated using small inocula $(0.01$ and $0.001 \mathrm{ml})$ in $\mathrm{NB}+\mathrm{NO}_{3}$ medium as well as ZoBell agar plates incubated aerobically. This RAPD genotype is assumed to be present in the highest abundance within the water column of the Gotland Deep. With respect to enrichment conditions, the selection of RAPD genotype $F$ seemed to be favored using high concentrations of organic matter, as indicated by its enrichment using NB media and ZoBell agar.

\section{Ecological niching versus physical transport processes}

The distribution of the RAPD genotypes in the water column can be based on 2 rather different phenomena, i.e. ecological niching vs physical transport processes. Ecological niching implies a specific adaptation of a given RAPD genotype to a specific environment. The suboxic zone of the water column is the favored habitat for Shewanella putrefaciens (see below). S. putrefaciens has been demonstrated to show taxis toward specific electron acceptors (Nealson et al. 1995). For this reason, niching could at least partially be assumed responsible for the distribution for $S$. putrefaciens RAPD genotypes in the water column.

Physical transport processes, on the other hand, may counteract the ecological niching by Shewanella putrefaciens. As described by Stigebrandt (1987), vertical transport, i.e. diffusive and convective, processes distribute bacteria upwards in the water column whereas interleaving water masses cause horizontal distribution. Bacteria attached to particles may be transported down with the sinking particles (Smetacek 1980). These physical transport processes may cause transfer of $S$. putrefaciens out of its preferred environment to a place where no growth, but survival, is possible. The stable stratification in the Gotland Deep during both years makes it likely that there was an accumulation of the $S$. putrefaciens RAPD genotypes in their favored environments.

Assuming that ecological niching is more important for the distribution of the RAPD genotypes than physical transport processes, the distribution patterns of the RAPD genotypes indicate that low oxygen and anoxic environments are preferred over oxic environments. As RAPD genotypes F and B of Shewanella putrefaciens were most abundant at the oxic-anoxic interface and at the bottom of the halocline, a specific role of these RAPD genotypes for the turnover of organic matter could be hypothesized.

\section{Stability of the Shewanella putrefaciens population structure over time}

Recent studies indicate that pelagic bacterial communities are rather stable over time (Giovannoni et al. 1990, Lee \& Fuhrman 1991, Fuhrman et al. 1993, Höfle \& Brettar 1995) and mainly consist of a few abundant species dominating the community (Höfle 1992, Rehnstam et al. 1993, Mullins et al. 1995). Most of these studies on the community structure of bacterioplankton are based on the direct molecular analysis of ribosomal RNA and have a taxonomic resolution of roughly the species level or less (Ward et al. 1992). 
Here, we describe the genetic structure of a pelagic bacterium, Shewanella putrefaciens, at a much finer scale, using DNA fingerprinting. Despite the disadvantage that population structure analysis is only possible with cultured bacterial isolates, the criteria observed for the structure of communities, i.e. stability over time and a limited number of abundant taxa, are also fulfilled for the investigated $S$. putrefaciens population. Although different media were employed for isolation of the strains, the population was observed to be dominated by 5 to 6 frequent RAPD genotypes that were present in both years, indicating a stability of the population over time. A certain stability, over time, was also reported for a Rhizobium meliloti population from Italian soils (Paffetti et al. 1996) and for a Burkholderia cepacia population in a river sediment (Wise et al. 1996) using sensitive methods for population analyses as well.

Taking into account that the respective media selected in favor of different RAPD genotypes, the genotypes may be assumed to exhibit different physiological traits. Thus, it is likely that the diversity of a bacterial community is higher than estimates from the direct analysis of stable RNAs indicate. Several different bacterial clones may 'hide behind' a common band or sequence of RNA.

In conclusion, it has been demonstrated by the use of a sensitive genotyping method that the isolation procedures are selective not only at the species level, but at the clonal level of a single species as well. Apart from the composition of the isolation medium and incubation conditions, the dilution step used for isolation has to be considered. Although different isolation procedures were used, the same frequent RAPD genotypes were obtained in both years. Therefore, this study demonstrated the stability of a population of a heterotrophic bacterial species over time in a pelagic habitat.

Acknowledgements. We gratefully acknowledge Markus G. Weinbauer for fruitful discussion and his help in improving the manuscript. We thank Edward R. Moore and 3 anonymous reviewers for valuable comments and suggestions. This study was supported by funds from the Commission of the European Communities and the Bundesministerium für Bildung, Wissenschaft, Forschung und Technologie (grant BEO0319433B).

\section{LITERATURE CITED}

Baalsrud K, Baalsrud KS (1954) Studies on Thiobacillus denitrificans. Arch Microbiol 20:34-62

Baranton G, Postic D, Saint-Girons I, Boerlin P, Piffaretti JC, Assous M, Grimont PAD (1992) Delineation of Borrelia burgdorferi sensu stricto, Borrelia garinii sp. nov., and group VS461 associated with Lyme borreliosis. Int J Syst Bacteriol 42:378-383

Brettar I, Höfle MG (1993) Nitrous oxide producing heterotrophic bacteria from the water column of the central
Baltic: abundance and molecular identification. Mar Ecol Prog Ser 94:253-265

Brettar I, Rheinheimer G (1991) Denitrification in the central Baltic: evidence for $\mathrm{H}_{2} \mathrm{~S}$-oxidation as motor of denitrification at the oxic-anoxic interface. Mar Ecol Prog Ser 77. 157-169

Brettar I, Rheinheimer G (1992) Influence of carbon availability on denitrification in the water column of the central Baltic Sea. Limnol Oceanogr 37:1146-1163

DiChristina TJ, DeLong EF (1993) Design and application of rRNA-targeted oligonucleotide probes for the dissimilatory iron- and manganese-reducing bacterium shewanella putrefaciens. Appl Environ Microbiol 59: $4152-4160$

Eisen D, Russell EG, Tymms M, Roper EJ, Grayson ML, Turnidge J (1995) Random amplified polymorphic DNA and plasmid analyses used in investigation of an outbreak of multiresistant Klebsiella pneumoniae. J Clin Microbiol 33:713-717

Fekete A, Bantle JA, Halling SM, Stich RW (1992) Amplification fragment length polymorphism in Brucella strains by use of polymerase chain reaction with arbitrary primers. J Bacteriol 174:7778-7783

Fuhrman JA, McCallum K, Davis A (1993) Phylogenetic diversity of subsurface marine microbial communities from the Atlantic and Pacific Oceans. Appl Environ Microbiol 59:1294-1302

Giovannoni SJ, Britschgi TB, Moyer CL, Field KG (1990) Genetic diversity in Sargasso Sea bacterioplankton. Nature 345:60-63

Höfle MG (1992) Aquatic microbial community structure and dynamics during large scale release of bacteria as revealed by low-molecular-weight RNA analysis. Appl Environ Microbiol 58:3387-3394

Höfle MG, Brettar I (1995) Taxonomic diversity and metabolic activity of microbial communities in the water column of the central Baltic. Limnol Oceanogr 40:868-874

Höfle MG, Brettar I (1996) Genotyping of heterotrophic bacteria from the central Baltic Sea using low-molecularweight RNA profiles. Appl Environ Microbiol 62: $1383-1390$

Lee SH, Fuhrman JA (1991) Spatial and temporal variation of natural bacterioplankton assemblages studied by total genomic DNA cross-hybridization. Limnol Oceanogr 36: $1277-1287$

McArthur JV, Kovacic DA., Smith MH (1988) Genetic diversity in natural populations of a soil bacterium across a landscape gradient. Proc Natl Acad Sci 85:9621-9624

Milkman R (1973) Electrophoretic variation in Escherichia coli from natural sources. Science 182:1024-1026

Mullins TD, Britschgi TB, Krest RL, Giovannoni SJ (1995) Genetic comparisons revealed the same unknown bacterial lineages in Atlantic and Pacific bacterioplankton communities. Limnol Oceanogr 40:148-158

Nealson KH, Moser DP, Saffarini DA (1995) Anaerobic electron acceptor chemotaxis in Shewanella putrefaciens. Appl Environ Microbiol 61:1551-1554

Nealson KH, Myers CR (1992) Microbial reduction of manganese and iron: new approaches to carbon cycling. Appl Environ Microbiol 58:439-443

Nealson KH, Myers CR, Wimpee BB (1991) Isolation and identification of manganese-reducing bacteria and estimates of microbial Mn (IV)-reducing potential in the Black Sea. Deep Sea Res 38:907-920

Nealson KH, Saffarini D (1994) Iron and manganese in anaerobic respiration: environmental significance, physiology and regulation. Ann Rev Microbiol 48:311-343 
Oppenheimer $\mathrm{CH}$, ZoBell CE (1952) The growth and viability of sixty-three species of marine bacteria as influenced by hydrostatic pressure. J Mar Res 11:10-18

O'Rourke M. Stevens E (1993) Genetic structure of Neisseria gonorrhoeae populations: a non-clonal pathogen. J Gen Microbiol 139:2603-2611

Paffetti D. Scotti C, Gnocchi S, Fancelli S, Bazzicalupo M (1996) Genetic diversity of an Italian Rhizobium meliloti population from different Medicago sativa varieties. Appl Environ Microbiol 62:2279-2285

Rasmussen HN, Olsen JE, Rasmussen OF (1994) RAPD analysis of Yersinia enterocolitica. Lett Appl Microbiol 19:359-362

Rehnstam AS, Bäckma S, Smith DC, Azam F, Hagström A (1993) Blooms of sequence-specific culturable bacteria in the sea. FEMS Microbiol Ecol 102:161-166

Rheinheimer GK, Gocke K, Hoppe HG (1989) Vertical distribution of microbiological and hydrographic-chemical parameters in different areas of the Baltic Sea. Mar Ecol Prog Ser 52:55-70

Saitou N, Nei M (1987) The neighbor-jolning method: a new method for reconstructing phylogenetic trees. Mol Biol Evol 4:406-425

Savchuk O, Wulff F (1996) Biogeochemica! transformations of nitrogen and phosphorus in the marine environment: coupling hydrodynamic and biogeochemical processes in models for the Baltic proper. Contrib Syst Ecol, Stockholm Univ 2:79

Segovia L, Piñero D, Palacios R, Martínez E (1991) Genetic structure of a soil population of nonsymbiotic Rhizobium leguminosarum. Appl Environ Microbiol 57:426-433

Selander RK, Caugant DA, Whittam TS (1987) Genetic structure and variation in natural populations of Escherichia coli. In: Neidhardt FC, Ingraham JL, Low KB, Magasanik B, Schaechter M, Umbarger HE (eds) Escherichia coli and Salmonella typhimurium. Cellular and molecular biology. American Society for Microbiology, Washington, DC, p 1625-1648

Selander RK, Levin BR (1980) Genetic diversity and structure in Escherichia coli populations. Science 210:545-547

Smetacek V (1980) Annual cycle of sedimentation in relation to plankton ecology in western Kiel Bight. Ophelia Suppl 1:65-76

Sokal RR, Michener CD (1958) A statistical method for evaluating systematic relationships. Univ Kansas Sci Bull $28: 1409-1438$

Responsible Subject Editor: G. Bratbak, Bergen, Norway
Sreenivasan A, Venkataraman R (1956) Marine denitrifying bacteria from south India. J Gen Microbiol 15:241-247

Stephan R, Schraft H, Untermann F (1994) Characterization of Bacillus licheniformis with the RAPD technique (randomly amplified polymorphic DNA). Lett Appl Microbiol 18: $260-263$

Stigebrandt A (1987) A model for the vertical circulation of the Baltic Deep water. J Phys Oceanogr 17:1772-1785

Stigebrandt A, Wulff $F$ (1987) A model for the dynamics of nutrients and oxygen in the Baltic proper. $J$ Mar Res 45: $729-759$

van Rossum D, Schuurmans FP, Gillis M, Muyotcha A, van Verseveld HW, Stouthamer A.H, Boogerd FC (1995) Genetic and phenetic analyses of Bradyrhizobium strains nodulating peanut (Arachis hypogaea L.) roots. Appl Environ Microbiol 61:1599-1609

Wang G, Whittam TS, Berg CM, Berg DE (1993) RAPD (arbitrary primer) PCR is more sensitive than multilocus enzyme electrophoresis for distinguishing related bacterlal strains. Nucleic Acids Res 21:5930-5933

Ward DM, Bateson MM, Weller R, Ruff-Roberts AL (1992) Ribosomal RNA analysis of microorganisms as they occur in nature. Adv Microb Ecol 12:220-286

Welsh J, McClelland M (1990) Fingerprinting genomes using PCR with arbitrary primers. Nucleic Acids Res 18: $7213-7218$

Welsh J, Pretzman C, Postic D, Saint-Girons I, Baranton G, McClelland $M$ (1992) Genomic fingerprinting by arbitrarily primed polymerase chain reaction resolves Borrelia burgdorferi into three distinct phyletic groups. Int $J$ Syst Bacteriol 42:370-377

Williams JGK, Kubelik AR, Livak KJ, Rafalski JA, Tingey SV (1990) DNA polymorphisms amplified by arbitrary primers are useful as genetic markers. Nucleic Acids Res 18: $6531-6535$

Wise MG, McArthur JV, Wheat C, Shimkets LJ (1996) Tem poral variation in genetic diversity and structure of a lotic population of Burkholderia (Pseudomonas) cepacia. Appl Environ Microbiol 62:1558-1562

Wise MG, Shimkets LJ, McArthur JV (1995) Genetic structure of a lotic population of Burkholderia ( $P$ seudomonas) cepacia. Appl Environ Microbiol 61:1791-1798

Wulff $F_{1}$ Stigebrandt A, Rahm L (1990) Nutrient dynamics of the Baltic Sea. Ambio 19:126-133

Manuscript received: October 21, 1996

Revised version accepted: January 31, 1997 